\title{
Differentiation ability of rat-mesenchymal stem cells from bone marrow and adipose tissue to neurons and glial cells
}

\author{
Ariyani Noviantari ${ }^{1{ }^{*}}$, Ratih Rinendyaputri ${ }^{1}$, Ibnu Ariyanto ${ }^{2}$ \\ ${ }^{1}$ Centre for Research and Development of Biomedical and Basic Health Technology, National Institute of Health Research and Development \\ (NIHRD), Ministry of Health, Republic of Indonesia, Jalan Percetakan Negara No. 23, Jakarta 10560, Indonesia \\ ${ }^{2}$ Virology and Cancer Pathobiology Research Center, Faculty of Medicine, Universitas Indonesia, Jalan Salemba Raya No. 4, Jakarta 10430, \\ Indonesia \\ ${ }^{*}$ Corresponding author: ariyani.noviantari@gmail.com
}

SUBMITTED 19 February 2020 REVISED 22 April 2020 ACCEPTED 3 June 2020

\begin{abstract}
Mesenchymal stem cells (MSCs) are multipotent cells and can differentiate into neurons and glial cells. In vitro differentiation would be done by the addition of various factors. There remains no comparison for the differentiation of MSCs from rat bone marrow (rBMMSCs) and adipose tissue (rATMSCS) into neurons and glial cells with basic fibroblast growth factor (bFGF), epidermal growth factor (EGF), and brain-derived neurotrophic factor (BDNF). The aims of this study were to investigate the effect of bFGF, EGF, and BDNF supplementation on the differentiation ability of rBMMSCs and rATMSCs into neurons and glial cells. MSCs were cultured with bFGF and EGF for 4 days and then BDNF was added until day 8. Characterization of MSCs before and after induction was carried out by observing the cell morphology and several cell markers. Flowcytometry analysis was performed for MSCs markers (CD90, CD29) and neurons and glial cell markers (A2B5, Beta-III-tubulin, PSAN-CAM); while MAP-2, a neuron marker, was analyzed by immunocytochemistry. Induction of both types of MSCs showed MAP-2-positive cells, decreased MSCs markers, and in rBMMSCs showed increased neuron markers. The number of neuron marker positive cells in rBMMSCS was higher than rATMSCs. This study showed that the addition of bFGF, EGF, and BDNF to the medium induced rBMMSCs into neurons and glial cells, but the conditions were not optimal for rATMSC as judged by the expression of neural markers (A2B5, Beta-III-tubulin, PSAN-CAM, and MAP-2).
\end{abstract}

KEYWORDS differentiation; glial cells; growth factors; mesenchymal stem cells (MSCs); neurons

\section{Introduction}

The Mesenchymal stem cells (MSCs) are undifferentiated cells that have the ability of self-renewal and differentiate into other cells (Dominici et al. 2006). MSCs are also multipotent; MSCs are capable of proliferating and differentiating into several constituent cells of the body such as osteoblasts, chondrocytes, adipocytes, neurons, and glial cells. The Mesenchymal stem cells (MSCs) can differentiate into various cell types provides opportunities in cell utilization as a therapy cell, especially in neurodegenerative diseases (Halim 2010). Neurons and glial cells derived from MSCs would offer an advantage for cell therapy in the future for the regeneration of neurons and glial cells in neurodegenerative diseases like spinal cord injury $(\mathrm{Qu}$ and Zhang 2017).

The Mesenchymal stem cells (MSCs) can be obtained from adult tissues such as bone marrow, adipose tissue, peripheral blood, cord blood, tendons, and ligaments (Sandhaanam et al. 2013). MSCs from the bone marrow can be obtained in small amounts and are more invasive (Bagha- ban Eslaminejad et al. 2008). MSCs from adipose tissue are easily obtained in large quantities through liposuction and easily propagated in vitro (Ikegame et al. 2011). MSCs from bone marrow and adipose tissue are also able to differentiate into osteoblasts, chondrocytes, adipocytes, neurons, and glial cells (Safford et al. 2004; Rebelatto et al. 2008; Tohill et al. 2004).

Induction of MSCs differentiation into neurons and glial cells can be done by adding various neurotrophic factors, growth factors, and chemicals in vitro. Several studies have reported that nerve growth factor (NGF), brainderived neurotrophic factor (BDNF), and neurotrophin3 (NT-3) are important neurotrophic factors in inducing the proliferation and differentiation of neural stem cells (Naghdi et al. 2009; Chen et al. 2014). In addition, several growth factors such as epidermal growth factor (EGF), basic fibroblast growth factor (bFGF), insulin-like growth factor-1 (IGF-1), glial growth factor (GGF), and bone morphogenetic protein-4 (BMP-4) supplementation to the culture medium can induce MSCs to neurons and glial cells (Tohill et al. 2004; Liang et al. 2013; Guan et al. 2014). 
The MSCs differentiation into neurons and glial cells in vitro can be characterized by the expression of neurons and glial cells markers. A2B5 is an immature glial marker in the brain area of the subventricular zone (SVZ) that will develop into astrocytes and oligodendrocytes; and it is widely expressed in embryonic and neonatal neural networks (Dietrich et al. 2002; van Strien et al. 2014). PSAN-CAM is a neuron progenitor cell or glial progenitor cell marker during brain development (neurogenesis) (Zhang and Jiao 2015). PSAN-CAM is also reported to be a marker of the development and migration of neurons and synapse formation in the immature nervous system (Quartu et al. 2008). Beta-III-tubulin (Tuj1) is a neuron marker that begins to be expressed in the embryonic phase of brain development and often found in post-mitotic neurons that are still immature (und Halbach 2007). MAP-2 is a cytoskeletal protein needed for the proliferation, development, differentiation, and maintenance of neurons (Soltani et al. 2005; Liu et al. 2001).

Previous studies have reported the role of combinations of several growth factors and neurotrophic factors in differentiation into neurons and glial cells. MSCs secrete the growth factors and neurotrophic factor-like EGF, bFGF, and BDNF in the conditioned medium (Wilkins et al. 2009; Pawitan 2014). bFGF plays a role in cell growth, differentiation, and survival (Yang et al. 2008). EGF also plays a role in maintaining cell proliferation and differentiation. The addition of both growth factors (EGF and bFGF) into MSCs culture medium is also reported to increase cell proliferation and support MSCs differentiation into neurons and glial cells (Radtke et al. 2009; Hu et al. 2013). BDNF plays a role in the differentiation, development, survival of neuron stem cells, axon regeneration, and synapse formation (Lim et al. 2008). The addition of growth factors (bFGF, EGF, and BDNF) to the culture medium can be used to induce MSCs differentiation into neurons and glial cells. Nevertheless, the role of these three factors in the differentiation of MSCs from bone marrow and adipose tissue is unknown. Therefore, this study aimed to investigate the effect of bFGF, EGF, and BDNF supplementation on the differentiation ability of rBMMSCs and rATMSCs into neurons and glial cells by observing their markers (A2B5, Beta-III-tubulin, PSAN$\mathrm{CAM}$, and MAP-2) to provide basic theoretical data for further research.

\section{Materials and Methods}

The study was conducted at the Stem Cell Laboratory, Centre for Research and Development of Biomedical and Basic Health Technology (CRDBBHT), National Health Research and Development Institute (NIHRD), Ministry of Health of the Republic of Indonesia from March to October 2017.

\subsection{Isolation and culture of rat MSCs from bone mar- row and adipose tissue}

The male Sprague Dawley (SD) rats at age of 2-3 months and weighed 200-300 g were used in this study. The animals were obtained from the Animal Laboratory, CRDBBHT, NIHRD, Ministry of Health of the Republic of Indonesia. The animals were handled in compliance with the regulation of local animal welfare facility rules. Isolation of rat adipose tissue and bone marrow from femur and tibia bones were performed under anesthesia with ketamine $(75-100 \mathrm{mg} / \mathrm{kg})$ in mixture with xylazine (5-10 $\mathrm{mg} / \mathrm{kg}$ ) via intraperitoneal injection. This procedure has been approved by the ethical committee of NIHRD.

Isolation of MSCs from the femur and tibia bones of rat (rat bone marrow MSCs, rBMMSCs) was done by cutting off each bone and flushing modification methods by a modified method of Rinendyaputri and Noviantari (2015), by flushing the bones with a syringe of MEM culture medium (Sigma) supplemented with 10\% fetal bovine serum (FBS) (Gibco), sodium bicarbonate (Sigma), nonessential amino acids 1\% (Sigma), mercaptoethanol 0.1 $\mathrm{mM}$ (Sigma), and gentamicin (Sigma). The cells were incubated in a $5 \% \mathrm{CO}_{2}$ incubator (Heracell Vios 160i) at 37 ${ }^{\circ} \mathrm{C}$. The culture medium was replaced after MSCs attached in 2-3 d (Rinendyaputri and Noviantari 2015).

Isolation of MSCs from rat adipose tissue (rATMSCs) was done by washing the adipose tissue in phosphatebuffered saline (PBS) supplemented with 1\% gentamicin in a petri dish. Adipose tissue was chopped into pieces $\left( \pm 2-3 \mathrm{~mm}^{2}\right)$ using sterile scissors and inserted into a conical tube containing a $0.075 \%$ type I collagenase solution (Gibco) with a ratio of 1:2 of adipose tissue to collagenase solution. The mixture was incubated in a water bath at $37^{\circ} \mathrm{C}$ for $1 \mathrm{~h}$ with shaking every $5 \mathrm{~min}$. After incubation, the mixture was centrifuged at $1400 \mathrm{rpm}$ for $10 \mathrm{~min}$, then the supernatant was removed, and PBS was added to the pellet. The suspension was filtered with a $70 \mu \mathrm{m}$ cell strainer (or electroplated tea filters). The filtered cell suspension was centrifuged again at $1400 \mathrm{rpm}$ for $10 \mathrm{~min}$ and the supernatant was removed. The pellets were resuspended with a culture medium (MEM supplemented with 10\% FBS, sodium bicarbonate, 1\% non-essential amino acids, $0.1 \mathrm{mM}$ mercaptoethanol, gentamicin, and GlutaMAX [Gibco]). MSCs from adipose tissue were cultured in an incubator with $5 \% \mathrm{CO}_{2}$ at $37{ }^{\circ} \mathrm{C}$. The medium was replaced every 2-3 d. Cells that have been confluent $80 \%$ are ready to passage.

When MSCs were nearly confluent (70-80\%), the cells were passaged with trypsin-EDTA (Gibco). The medium was removed. Cells were washed twice with PBS. Trypsin-EDTA was added to the cells, and the cells were incubated for $5 \mathrm{~min}$ at $37^{\circ} \mathrm{C}$. The cells were suspended in the culture medium. The number of cells was counted with a Neubauer hemacytometer cell counting chamber after trypan blue staining. The cells were replated in a 12well plate $\left(1 \times 10^{5}\right.$ cells per well), and cells were incubated at $37^{\circ} \mathrm{C}$ in the culture medium. The medium was replaced 


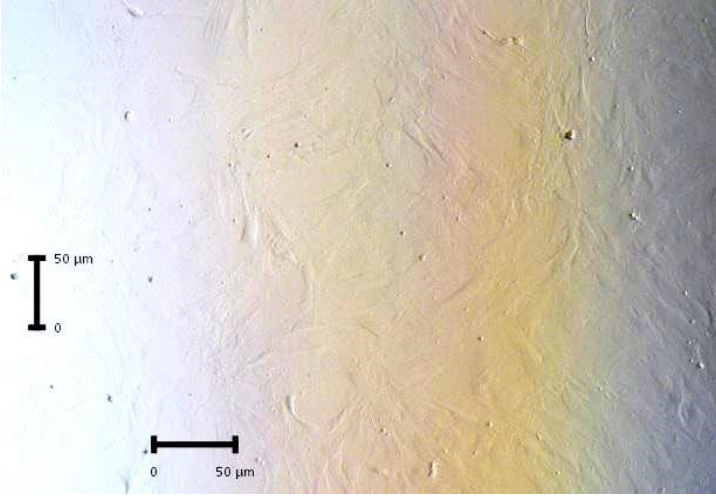

(a)

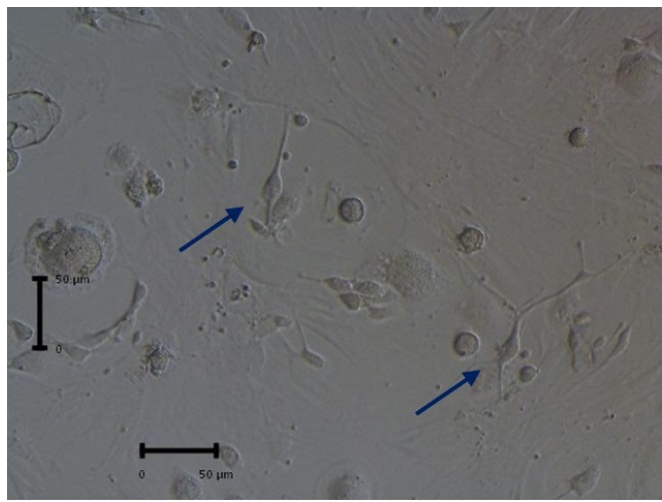

(c)

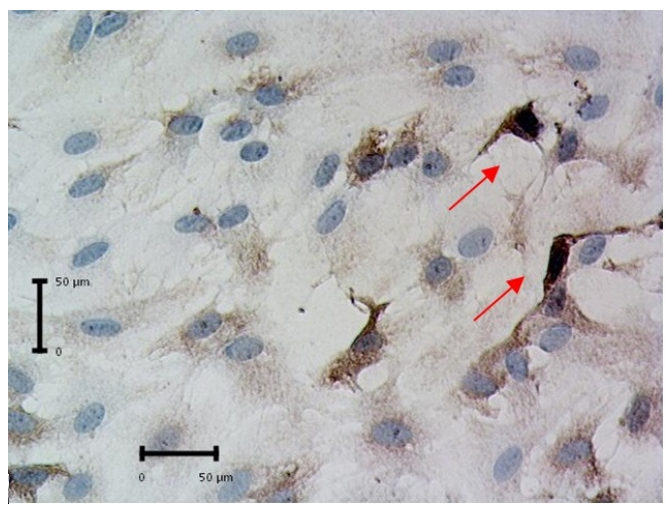

(e)

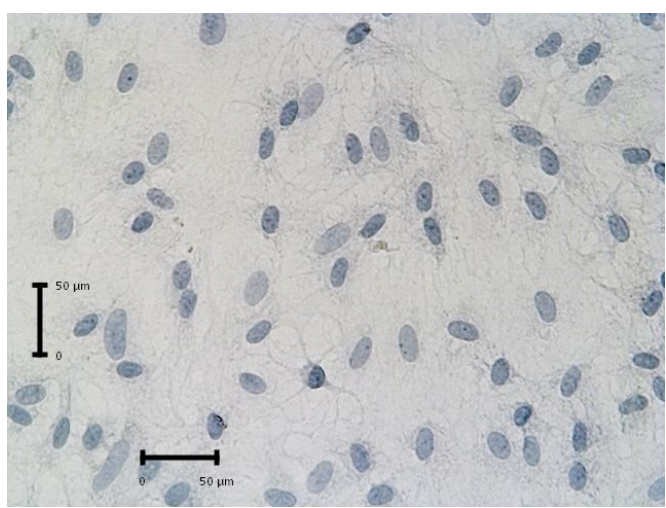

(g)

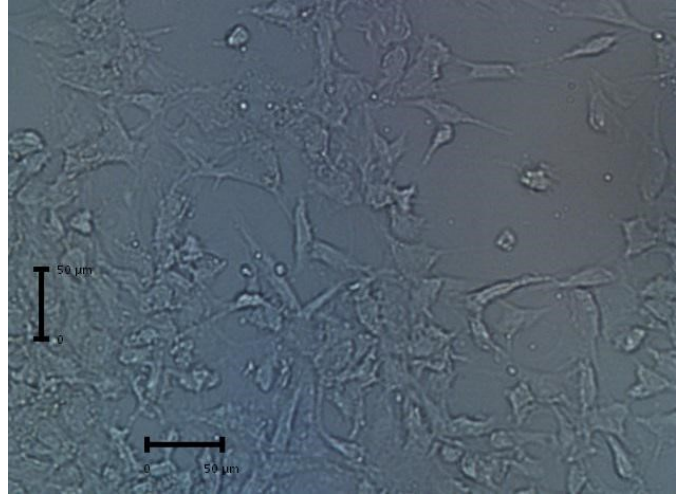

(b)

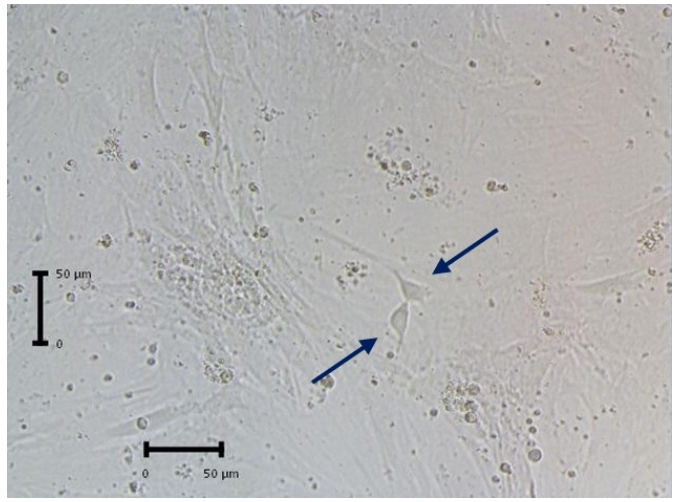

(d)

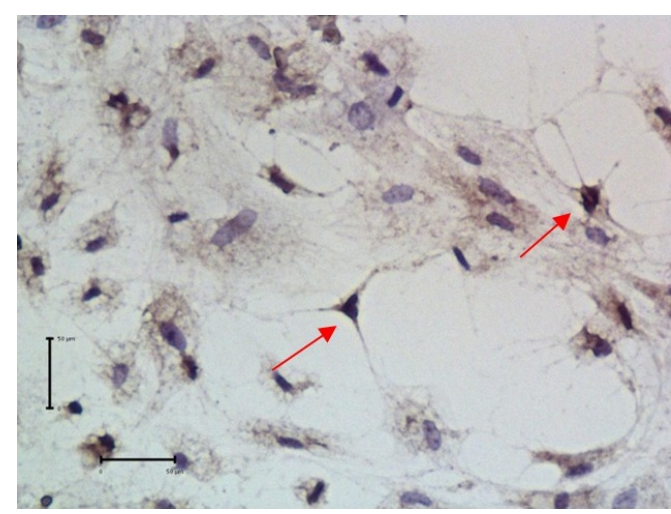

(f)

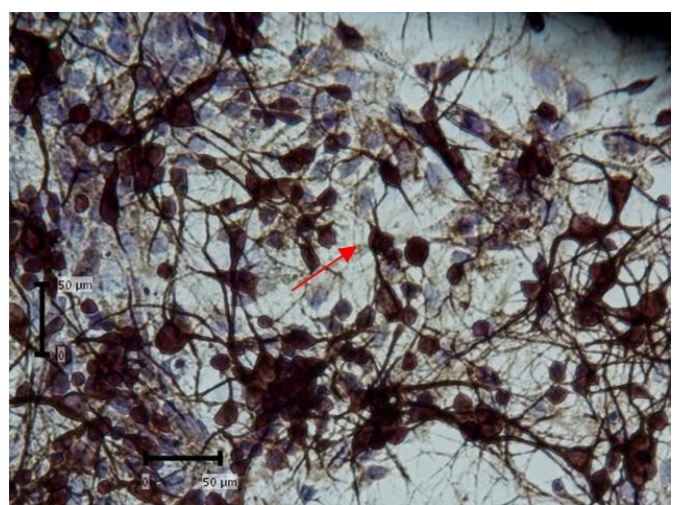

(h)

FIGURE 1 Morphology of MSCs before and after induction. (a-b) Morphology of rBMMSCs (a) and rATMSCs (b) after $5 \mathrm{~d}$ of primary culture were depicted before induction. Cells were isolated from 3-month-old rats. (c-d) Morphology of rBMMSCs (c) and rATMSCs (d) $8 \mathrm{~d}$ after induction with bFGF, EGF, and BDNF. Blue arrows indicate neuron-like cells. (e-f) Expression of MAP-2 as a mature neuron marker (red arrows) after induction. Representative pictures after MAP-2 staining in rBMMSCs (e) and rATMSCs ( $\mathrm{f}$ ) are shown. Negative control (g) and positive control (h) are shown. The brown cells indicate MAP-2-positive cells. 
every 2-3 d.

\subsection{Induction of MSCs neural differentiation with bFGF, EGF, and BDNF}

Induction methods of MSCs neural differentiation were modified from Anghileri et al. (2008) by changing Dulbecco's modified Eagle's medium with Neurobasal medium, omitting retinoic acid (RA) to induce MSCs, and omitting the isolation of spherical floating aggregates after incubation with bFGF and EGF. The MSCs at the passage (P3) were harvested by trypsinization and then were centrifuged. The pellet was resuspended in the induction medium on a 12-well plate (in duplicate). The induction consisted of 2 stages: (1) the cells were cultured in Neurobasal medium supplemented with bFGF and EGF (20 ng/mL) containing 10\% FBS, 2\% B27 supplement (Gibco), antibiotic and antimycotic, and GlutaMAX for $4 \mathrm{~d}$; (2) the cells were cultured with the same medium as (1) with the addition of BDNF (20 ng/mL) until day 8. The cells were incubated in a $5 \% \mathrm{CO}_{2}$ incubator at $37^{\circ} \mathrm{C}$. The induction medium was replaced every 2-3 $\mathrm{d}$. Induced MSCs were observed under an inverted microscope (Nikon ECLIPSE TE2000-U) with NIS-Elements F Imaging Software. Flowcytometry analysis of A2B5, beta-III-tubulin, and PSA-NAM; and immunocytochemistry of MAP-2 were conducted on day 8.

\subsection{Flowcytometry}

In this study, rBMMSCs and rATMSCS were characterized with CD29+, CD90+, and CD45- (Biolegend). Induced MSCs were characterized by using A2B5-, PSAN$\mathrm{CAM}+$ (Miltenyi Biotec), and Beta-III-tubulin (Biolegend) markers according to the instruction kit. The flowcytometry analysis was performed by using a BD Accuri C6 Plus. Flowcytometry data analyzed with Flowjo V10: population gated by total MSC, the single cells; and the markers of MSCs, neurons, and glial cells. The control population was stained with isotype antibodies. Gates were drawn based on matched isotype control cocktails.

\subsection{MAP-2 immunocytochemistry of induced MSCs}

Immunocytochemistry of neural differentiation-induced MSCs was adopted from Stephanie et al. (2013) by decreasing the incubation time. The medium was discarded from the well then washed with PBS twice. Fixation was done by incubating induced MSCs in 4\% paraformaldehyde (PFA) for 15 min, then washed with PBS three times each for $5 \mathrm{~min}$. Blocking steps were performed by blocking endogenous peroxidase with $3 \%(\mathrm{v} / \mathrm{v}) \mathrm{H}_{2} \mathrm{O}_{2}$ in methanol (Merck K38122297) for 15 min, and by blocking nonspecific backgrounds with background snipper (Starr Trek Universal HRP Detection Kit Biocare) for 15 min. Cells were washed in PBS three times each for 5 min. Then, cells were incubated with MAP-2 primary antibody (Santa Cruz sc-74421) at $4{ }^{\circ} \mathrm{C}$ overnight and washed in PBS three times each for $5 \mathrm{~min}$. Cells were incubated with secondary HRP-conjugated antibody (Trekkie Universal Link, Starr Trek Universal HRP Detection Kit Bio- care ${ }^{\circledR)}$ for $15 \mathrm{~min}$, then cells were washed in PBS for 5 min. After that, cells were incubated with Trek-AvidinHRP (Starr Trek Universal HRP Detection Kit Biocare) for $15 \mathrm{~min}$, followed by washing in PBS for $5 \mathrm{~min}$. Chromogen substrate diamino-benzidine (DAB) dissolved in substrate buffer (Starr Trek Universal HRP Detection Kit Biocare) were added and incubated for 1-2 min, then cells were washed with ultrapure water (Milli-Q, Merck), water for 10 min. Cells were counterstained with Hematoxylin Mayer (Biocare 3570) for 1-2 min and washed in ultrapure water for $5 \mathrm{~min}$.

Positive and negative controls were included in every staining protocol. Positive control for MAP-2 immunocytochemistry was primary neuron culture from rat brain. MAP-2-positive cells were indicated by brown color in the cytoplasmic and nucleus area. The negative control was obtained by omitting MAP-2 primary antibody.

\subsection{Data analysis}

Data on percentage of MSCs, neuron, and glial marker positive and negative were analyzed using Statistical Product and Service Solution (SPSS) 16. A comparison between groups was performed using a t-test with a $95 \%$ confidence level $(P<0.05)$.

\section{Results and Discussion}

Isolated MSCs from bone marrow and adipose tissue showed morphology dominated by cells such as fibroblast cells, then cells became confluent and monolayer (Figure $1 \mathrm{~A}$ and $1 \mathrm{~B})$. Immunophenotype analysis of rBMMSCs and rATMSCs at passage 3 (P3) before and after induction using flowcytometry showed that more than $50 \%$ of cells were CD29+ and CD90+ (MSCs markers) and less than 3\% cells were CD45+ (hematopoietic marker) (Figure 2A). After differentiation induction, the percentages of CD90, and CD29 positive were decreased. Decreases in the percentage of rBMMSCs markers (CD29 and CD90) positive cells before and after induction were as 1.95-, and 1.18- fold, respectively. The decrease in the percentage of rATMSCs markers (CD29) before and after induction was as 1.66- fold, while the percentage of CD90-positive cells in rATMSCs was slightly increased. The comparison between the percentage of CD29 of both MSCs showed a significant difference. Based on the paired sample ttest, CD29 had a significant difference with the p-value of 0.007 for rBMMSCs and 0.004 for rATMSCs before and after induction. Comparison between rBMMSCs and rATMSCs after induction showed that CD29 was significantly different $(P<0.05)$.

Induced MSCs showed morphology change after induction with bFGF, EGF, and BDNF. Both MSCs showed characteristics of neuron-like morphology with a condensed nucleus, contracted cytoplasm (blue arrow) with two or three cellular processus like bipolar neurons and multipolar neurons (Figures 1C and 1D). MAP-2 expression in induced MSCs was observed on day 8 after the addition of bFGF, EGF, and BDNF. MAP-2 positive cells 


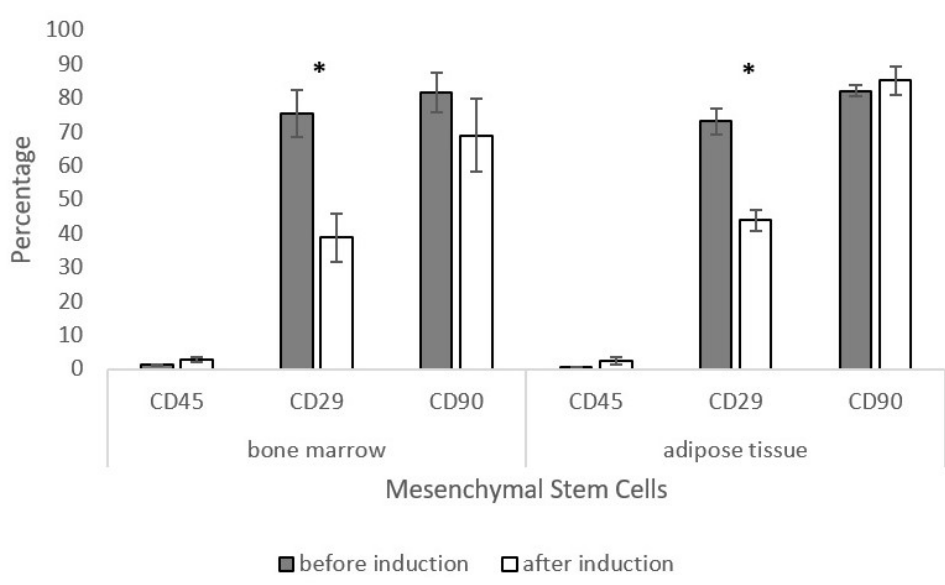

(a)
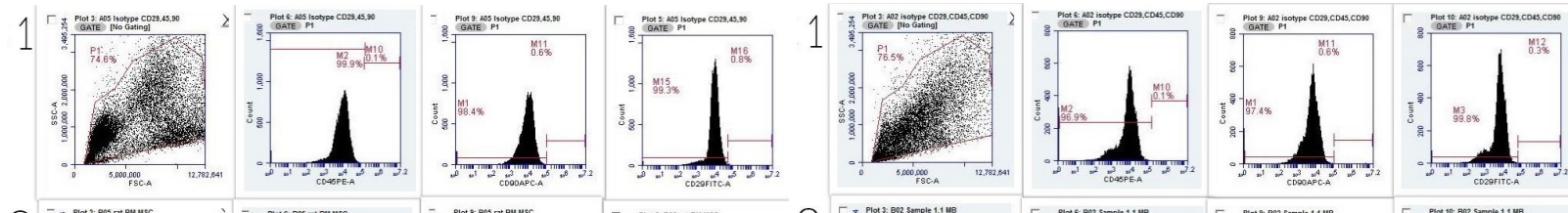

2
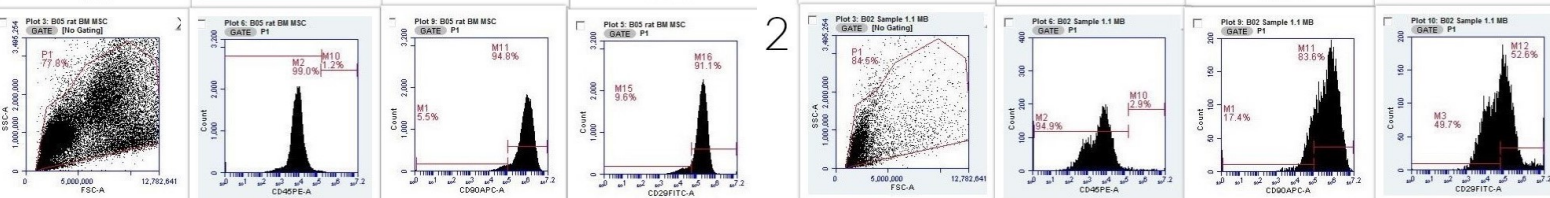

(b)
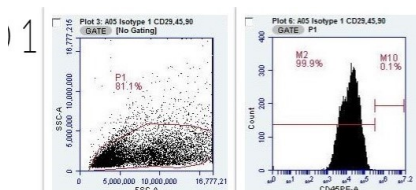

2

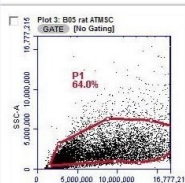

(d)

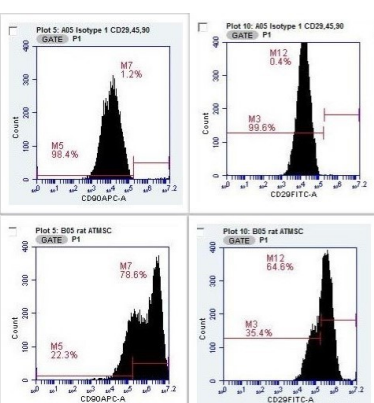

(c)
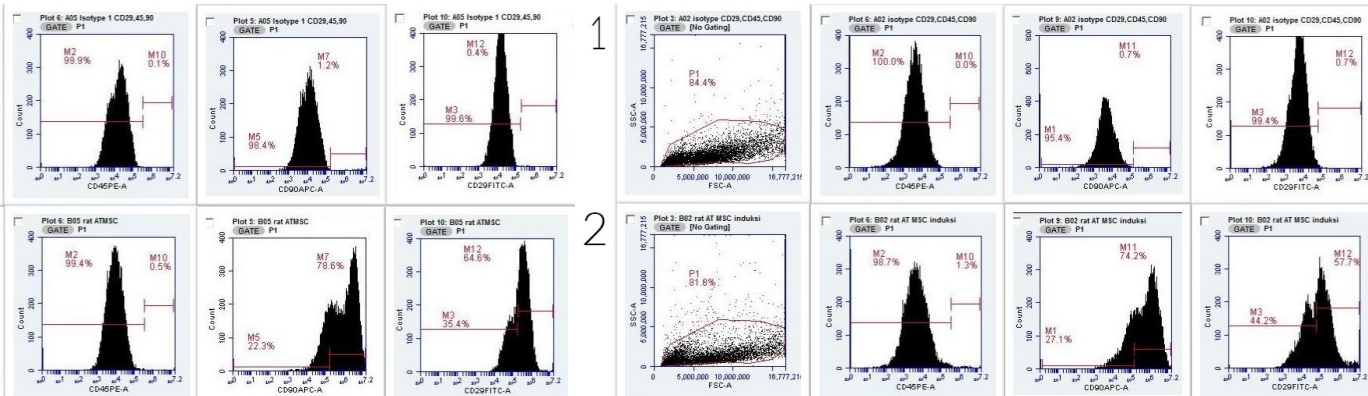

(e)
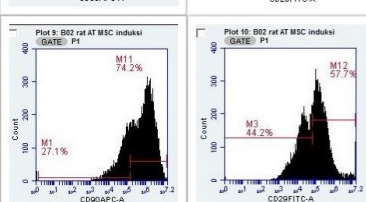

FIGURE 2 Characterization of MSCs before and after neuron induction. (a) Comparison of expression of CD45, CD29, and CD90 between rBMMSCs and rATMSCs before and after differentiation induction. The percentage of CD45 and CD29 from rBMMSCs and CD45 from rATMSCs showed a significant difference before and after induction ( $n=3$, three independent experiments in duplicate measurement for each experiment). Percentage of CD29 and CD90 after induction between rBMMSCs and rATMSCs showed a significant difference ( $\mathrm{n}=3$, three independent induction experiments in duplicate measurement for each experiment). ${ }^{*} P<0.05$. (b-e) Representative figures of flowcytometry analysis. Immunophenotype of MSCs marker of rBMMSCs before induction (b) and after induction (c). Immunophenotype of MSCs of rATMSCs before induction (d) and after induction (e). Each panel consists of (1) isotype control and (2) sample.

showed brown color in the cytoplasmic and nucleus area (red arrow) (Figure 1E and 1F). MAP-2-negative cells appeared as cells with bluish staining nucleus or hematoxylin stained nucleus (Figure 1G).

After induction with bFGF, EGF, and BDNF, rBMMSCs showed an increased percentage of positive cells for the glial progenitor maker, A3B5, and the immature neuron markers, beta-III-tubulin, and PSAN-CAM. Increases in the percentage of neuron markers A2B5-, betaIII-tubulin-, and PSAN-CAM-positive cells before and after induction of rBMMSCs were as 1.34-, 1.53-, and 1.47fold, respectively. But, rATMSCs show decreases in the percentage of neuron markers A2B5, beta-III-tubulin, and
PSAN-CAM before and after induction of rATMSCs were as 1.66-, 1.2-, and 2.03-fold, respectively (Figure 3A). Using a paired t-test, the comparison between the percentage of A2B5 of rBMMSCs before and after induction showed a significant difference. The percentage of A2B5 from rBMMSCs had a significant difference with p-value of 0.032 .

\subsection{Discussion}

Isolation and culture of rat bone marrow and rat adipose tissue MSCs were successfully performed, and isolated MSCs showed a high percentage of MSCs markers (CD90 and CD29) with a low percentage of hematopoietic surface markers (CD45). These results are consistent with the 


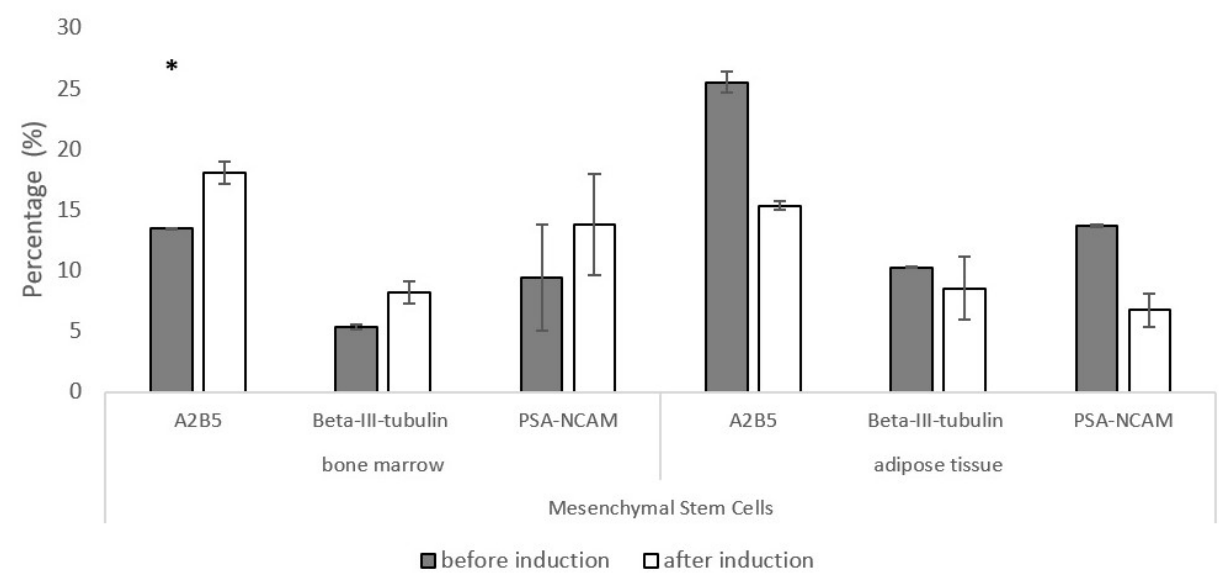

(a)
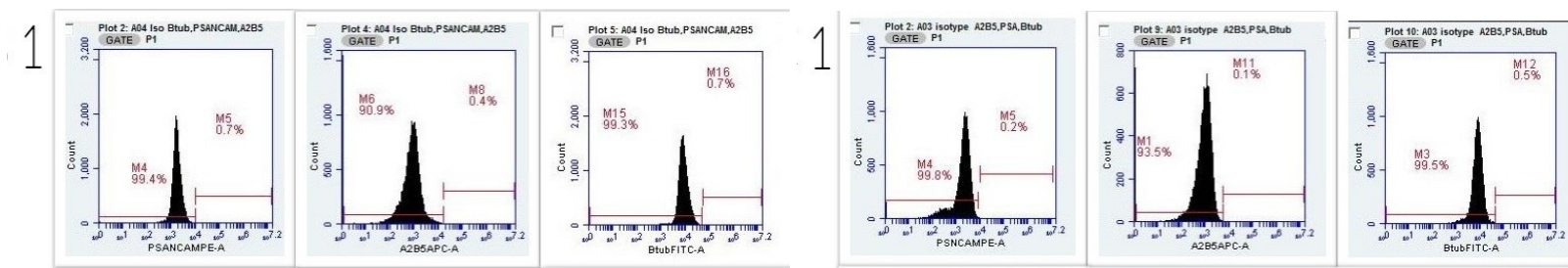

2
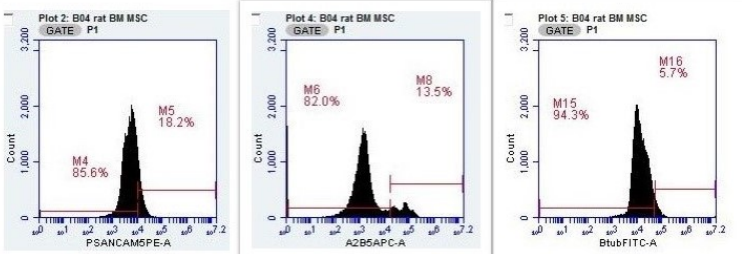

2
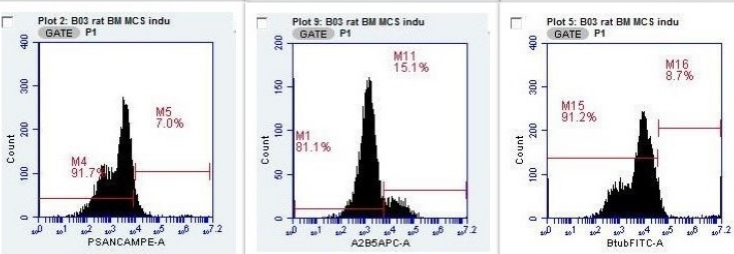

(b)
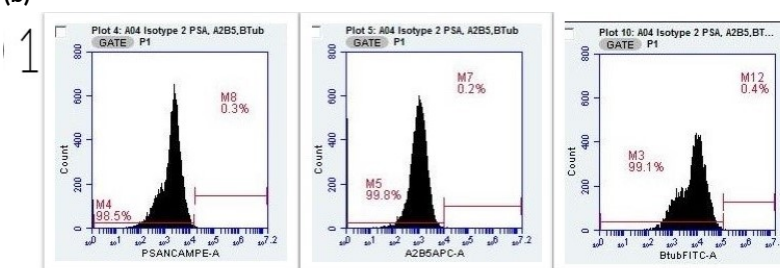

(c)

2
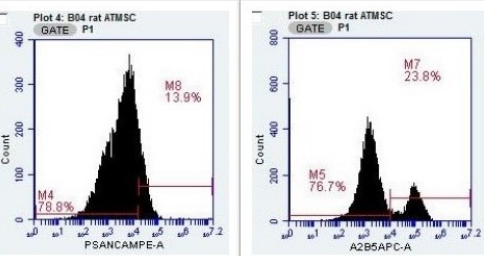

(d)
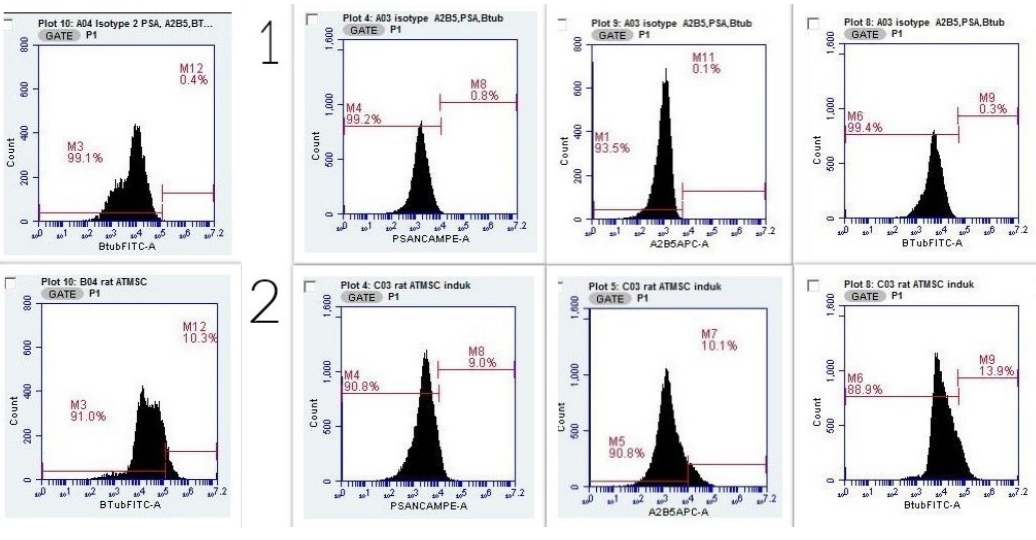

2
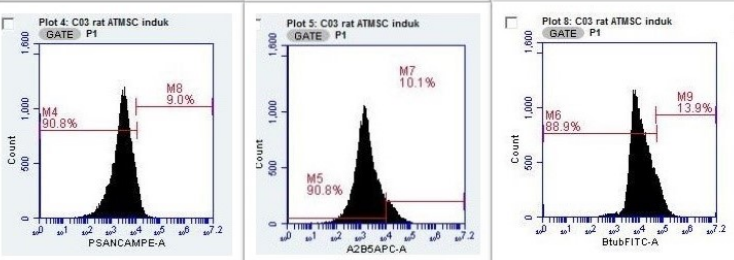

(e)

FIGURE 3 Characterization of neurons and glial cells. (a) Comparison of expression of PSA-NCAM, A2B5, and Beta-III-tubulin in rBMMSCs and rATMSCs before and after differentiation induction. Percentage of A2B5 and Beta-III-tubulin from rBMMSCs, PSA-NCAM, and Beta-III-tubulin from rATMSCs showed a significant difference before and after induction $(n=3$, three independent experiments in duplicate measurement for each experiment). $P<0.05$. (b-e) Representative figures of flowcytometry analysis. Immunophenotype of neurons and glial cells marker of rBMMSCs before (b) and after induction (c). Immunophenotype of neurons and glial cells marker of rATMSCs before (d) and after induction (e). Each panel consists of (1) isotype control and (2) sample.

MSCs criteria based on the International Society for Cellular Therapy (ISCT), which defines MSCs as cells able to attach to a plastic culture container, positive for CD90, CD73, CD105, and CD44, and negative for CD34, CD45, HLA-DR, and CD11b.1.

In this research, we used MSCs at passage 3 because in this passage, cells show high proliferation and high mul- tilineage differentiation capacity. The proliferation of the cells as determined by the cumulative population doubling level was observed at its peak on passage 3, and the proliferation stopped after passage 5 (Lee et al. 2013).

From our research, we have confirmed that rATMSCs and rBMMSCs express neuron markers spontaneously before induction. Deng et al. (2006) reported that although 
in the absence of specialized induction reagents, MSCs spontaneously express certain neuron phenotype markers. MSCs are positive for several neuron-specific proteins, including $\beta$-III tubulin (12\%) and NFM (13.2\%); negative for PSA-NCAM, a surface protein expressed on migratory neuroblasts; positive for the astrocyte-specific protein, S100- $\beta$ (15\%); but negative for the astrocyte intermediate filament proteins, GFAP, and vimentin (Deng et al. 2006).

In this study, retinoic acid (RA) was removed from the neural differentiation induction medium of Anghileri et al. (2008) because we wanted to know the role of the three growth factors (EGF, bFGF, and BDNF) exclusively in the differentiation of MSCs into neurons and glial cells to provide basic theoretical data for further research. Anghileri et al. (2008) used $30 \mathrm{~d}$ for induction and obtained neuron differentiation in 57\% of ATMSC. In this study, we induced MSCs with only 3 growth factors (bFGF, EFG, and BDNF) for $8 \mathrm{~d}$, and obtained 15\% of cells differentiated into neurons and glial cells. This efficiency is comparable to those reported previously. Jeon et al. (2007) reported that MSCs cultured in neuron pre-induction medium containing a combination of growth factors NT-3 (30 ng/mL) and bFGF (10 ng/mL) for 4-5 d followed by an induction medium containing NT- 3 (30 ng/mL) and BDNF (10 $\mathrm{ng} / \mathrm{mL}$ ) for $7 \mathrm{~d}$ produces Nestin-positive cells $(4.7 \pm 0.8 \%$ pre-induction and $14.2 \pm 2.0 \%$ post-induction).

In the present research, we omitted the isolation of spherical floating aggregates (neurosphere) after incubation with bFGF and EGF to make an easy and more efficient differentiation protocol. There are several studies of differentiation MSCs to neurons without neurosphere isolation steps. Guan et al. (2014) reported that rat MSCs from bone marrow differentiated to neurons by adding combinations of growth factors (EGF, bFGF, IGF-1, and NT-3) without neurosphere isolation (Guan et al. 2014). Ikegame et al. (2011) also reported that mice MSCs from bone marrow and adipose tissue differentiated to neurons and glial cells after $48 \mathrm{~h}$ with several chemical compounds without neurosphere isolation. The percentage of neuron marker from MSCs from adipose tissue was $40 \pm 6 \%$ (MAP-2), 14 $\pm 2 \%(\mathrm{NeuN}$ ), and 23 $\pm 5 \%$ (Nestin) (Ikegame et al. 2011).

In the differentiation of MSCs into neurons and glial, there are a variety of different markers according to the stages of differentiation (Rushing and Ihrie 2016). PSANCAM and A2B5 are markers of neurogenesis as a marker of an immature neuron and glial cells. This is in accordance with the previous research conducted by Czarnecka et al. (2017), which states that MSCs from the human umbilical cord can differentiate into neurons and glial cells using commercial neuron mediums (MSC Neurogenic Differentiation Medium) which produces NCAM+ (50,83 \pm $3.01 \%)$ and A2B5+ (19.97 $\pm 1.70 \%)$. In this study, a decrease in the percentage of neuron and glial markers may be due to the differentiation of MSCs that are already in the mature neuron stage with positive MAP-2 markers.

Our current result differs from that of Ikegame et al.
(2011), in which MSCs from adipose tissue showed a better efficacy in treating ischemic stroke in mice by injecting MSCs from adipose tissue or bone marrow. They reported that several tissue regenerative factors like vascular endothelial cell growth factor (VEGF), angiopoietin-1, and hepatocyte growth factor (HGF) from mouse ATMSCs are higher than BMMSCs Ikegame et al. (2011). Assessment of secreted growth factors from rBMMSCs and rATMSCS should be done to compare concentrations of growth and neurotrophic factors in the conditioned medium of both MSCs. Further, add more growth factors and characterization of neurons and glial cells induced from rBMMSCs and rATMSCS should also be done with another neural markers, i.e,. Nestin, NeuN, and GFAP.

\section{Conclusions}

The addition of bFGF, EGF, and BDNF to the medium induces rBMMSCs into neurons and glial cells, but the medium induction is not optimal for rATMSC by the expression of neural markers (A2B5, Beta-III-tubulin, PSAN-CAM, and MAP-2) and needs to be improved.

\section{Acknowledgments}

The authors would like to acknowledge the Director of Centre for Research and Development of Biomedical and Basic Health Technology (CRDBBHT), researchers at Stem Cell Laboratory and Animal Laboratory, CRDBBHT, NIHRD, Ministry of Health Republic of Indonesia for creating a conducive environment for completion of this study. This study was financially supported by the Ministry of Health of the Republic of Indonesia.

\section{Authors' contributions}

AN, RR designed the study and carried out the laboratory work. AN, IA analyzed the data. AN, RR, IA wrote the manuscript. All authors read and approved the final version of the manuscript.

\section{Competing interests}

The authors declare no competing interest.

\section{References}

Anghileri E, Marconi S, Pignatelli A, Cifelli P, Galié M, Sbarbati A, Krampera M, Belluzzi O, Bonetti B. 2008. Neuronal differentiation potential of human adiposederived mesenchymal stem cells. Stem Cells Dev. 17(5):909-916. doi:10.1089/scd.2007.0197.

Baghaban Eslaminejad M, Mardpour S, Ebrahimi M. 2008. Growth kinetics and in vitro aging of mesenchymal stem cells isolated from rat adipose versus bone marrow tissues. Iran J Vet Surg. 3(2):9-20. 
Chen SQ, Cai Q, Shen YY, Cai XY, Lei HY. 2014. Combined use of NGF/BDNF/bFGF promotes proliferation and differentiation of neural stem cells in vitro. Int $\mathrm{J}$ Dev Neurosci. 38:74-78. doi:10.1016/j.ijdevneu.2014.08.002.

Czarnecka J, Porowińska D, Bajek A, Hołysz M, Roszek K. 2017. Neurogenic differentiation of mesenchymal stem cells induces alterations in extracellular nucleotides metabolism. J Cell Biochem. 118(3):478486. doi:10.1002/jcb.25664.

Deng J, Petersen BE, Steindler DA, Jorgensen ML, Laywell ED. 2006. Mesenchymal stem cells spontaneously express neural proteins in culture and are neurogenic after transplantation. Stem Cells. 24(4):10541064. doi:10.1634/stemcells.2005-0370.

Dietrich J, Noble M, Mayer-Proschel M. 2002. Characterization of A2B5+ glial precursor cells from cryopreserved human fetal brain progenitor cells. Glia. 40(1):65-77. doi:10.1002/glia.10116.

Dominici M, Le Blanc K, Mueller I, Slaper-Cortenbach I, Marini F, Krause D, Deans R, Keating A, Prockop D, Horwitz E. 2006. Minimal criteria for defining multipotent mesenchymal stromal cells. The International Society for Cellular Therapy position statement. Cytotherapy. 8(4):315-317. doi:10.1080/14653240600855905.

Guan M, Xu Y, Wang W, Lin S. 2014. Differentiation into neurons of rat bone marrow-derived mesenchymal stem cells. Eur Cytokine Netw. 25(3):58-63. doi:10.1684/ecn.2014.0357.

Halim D. 2010. Stem Cell: Dasar Teori \& Aplikasi Klinis. Erlangga.

Hu F, Wang X, Liang G, Lv L, Zhu Y, Sun B, Xiao Z. 2013. Effects of epidermal growth factor and basic fibroblast growth factor on the proliferation and osteogenic and neural differentiation of adiposederived stem cells. Cell Reprogram. 15(3):224-232. doi:10.1089/cell.2012.0077.

Ikegame Y, Yamashita K, Hayashi SI, Mizuno H, Tawada M, You F, Yamada K, Tanaka Y, Egashira Y, Nakashima S, et al. 2011. Comparison of mesenchymal stem cells from adipose tissue and bone marrow for ischemic stroke therapy. Cytotherapy. 13(6):675685. doi:10.3109/14653249.2010.549122.

Jeon SJ, Oshima K, Heller S, Edge AS. 2007. Bone marrow mesenchymal stem cells are progenitors in vitro for inner ear hair cells. Mol Cell Neurosci. 34(1):5968. doi:10.1016/j.mcn.2006.10.003.

Lee K, Cha SH, Kang H, Song JY, Lee K, Ko K, Lee H. 2013. Effects of serial passage on the characteristics and chondrogenic differentiation of canine umbilical cord matrix derived mesenchymal stem cells. Asian-Australas J Anim Sci. 26(4):588. doi:10.5713/ajas.2012.12488.

Liang J, Wu S, Zhao H, Li Sl, Liu Zx, Wu J, Zhou L. 2013. Human umbilical cord mesenchymal stem cells derived from Wharton's jelly differentiate into cholinergic-like neurons in vitro. Neurosci Lett.
532:59-63. doi:10.1016/j.neulet.2012.11.014.

Lim JY, Park SI, Oh JH, Kim SM, Jeong CH, Jun JA, Lee KS, Oh W, Lee JK, Jeun SS. 2008. Brain-derived neurotrophic factor stimulates the neural differentiation of human umbilical cord blood-derived mesenchymal stem cells and survival of differentiated cells through MAPK/ERK and PI3K/Akt-dependent signaling pathways. J Neurosci Res. 86(10):21682178. doi:10.1002/jnr.21669.

Liu Y, Sturgis CD, Grzybicki DM, Jasnosz KM, Olson PR, Tong M, Dabbs DD, Raab SS, Silverman JF. 2001. Microtubule-associated protein-2: a new sensitive and specific marker for pulmonary carcinoid tumor and small cell carcinoma. Mod Pathol. 14(9):880. doi:10.1038/modpathol.3880406.

Naghdi M, Naghdi M, Tiraihi T, Namin SAM, Arabkheradmand J. 2009. Transdifferentiation of bone marrow stromal cells into cholinergic neuronal phenotype: a potential source for cell therapy in spinal cord injury. Cytotherapy. 11(2):137-152. doi:10.1080/14653240802716582.

Pawitan JA. 2014. Prospect of stem cell conditioned medium in regenerative medicine. BioMed Res Int. 2014. doi:10.1155/2014/965849.

Qu J, Zhang H. 2017. Roles of mesenchymal stem cells in spinal cord injury. Stem Cells Int. 2017. doi:10.1155/2017/5251313.

Quartu M, Serra MP, Boi M, Ibba V, Melis T, Del Fiacco M. 2008. Polysialylated-neural cell adhesion molecule (PSA-NCAM) in the human trigeminal ganglion and brainstem at prenatal and adult ages. BMC Neurosci. 9(1):108. doi:10.1186/1471-2202-9-108.

Radtke C, Schmitz B, Spies M, Kocsis J, Vogt P. 2009. Peripheral glial cell differentiation from neurospheres derived from adipose mesenchymal stem cells. Int J Dev Neurosci. 27(8):817-823. doi:10.1016/j.ijdevneu.2009.08.006.

Rebelatto C, Aguiar A, Moretao M, Senegaglia A, Hansen P, Barchiki F, Oliveira J, Martins J, Kuligovski C, Mansur F, et al. 2008. Dissimilar differentiation of mesenchymal stem cells from bone marrow, umbilical cord blood, and adipose tissue. Exp Biol Med. 233(7):901-913. doi:10.3181/0712-RM-356.

Rinendyaputri R, Noviantari A. 2015. Produksi Mesenchymal Stem Cell (MSC) Dari Sumsum Tulang Belakang Mencit. Indonesian Journal of Biotechnology Medicine 4(1):33-41. doi:10.22435/jbmi.v4i1.4211.33-41.

Rushing G, Ihrie RA. 2016. Neural stem cell heterogeneity through time and space in the ventricularsubventricular zone. Front Biol. 11(4):261-284. doi:10.1007/s11515-016-1407-1.

Safford K, Safford S, Gimble J, Shetty A, Rice H. 2004. Characterization of neuronal/glial differentiation of murine adipose-derived adult stromal cells. Exp Neurol. 187(2):319-328. doi:10.1016/j.expneurol.2004.01.027.

Sandhaanam SD, Pathalam G, Dorairaj S, Savariar V. 
2013. Mesenchymal stem cells (MSC): identification, proliferation and differentiation. Technical report, PeerJ PrePrints. doi:10.7287/peerj.preprints.148v1.

Soltani MH, Pichardo R, Song Z, Sangha N, Camacho F, Satyamoorthy K, Sangueza OP, Setaluri V. 2005. Microtubule-associated protein 2, a marker of neuronal differentiation, induces mitotic defects, inhibits growth of melanoma cells, and predicts metastatic potential of cutaneous melanoma. Am J Pathol. 166(6):1841-1850. doi:10.1016/S00029440(10)62493-5.

Stephanie M, et al. 2013. Analisis Hubungan antara Ekspresi MMP-2 dengan Derajat Neoplasia Serviks pada Pap Smear Berbasis Cairan. Majalah Patologi Indonesia 22(3).

Tohill M, Mantovani C, Wiberg M, Terenghi G. 2004. Rat bone marrow mesenchymal stem cells express glial markers and stimulate nerve regeneration. Neurosci Lett. 362(3):200-203. doi:10.1016/j.neulet.2004.03.077.

und Halbach OvB. 2007. Immunohistological markers for staging neurogenesis in adult hippocampus. Cell Tissue Res. 329(3):409-420. doi:10.1007/s00441-0070432-4.

van Strien ME, Sluijs JA, Reynolds BA, Steindler DA, Aronica E, Hol EM. 2014. Isolation of neural progenitor cells from the human adult subventricular zone based on expression of the cell surface marker CD271. Stem Cells Transl Med. 3(4):470-480. doi:10.5966/sctm.2013-0038.

Wilkins A, Kemp K, Ginty M, Hares K, Mallam E, Scolding N. 2009. Human bone marrow-derived mesenchymal stem cells secrete brain-derived neurotrophic factor which promotes neuronal survival in vitro. Stem Cell Res. 3(1):63-70. doi:10.1016/j.scr.2009.02.006.

Yang H, Xia Y, Lu SQ, Soong TW, Feng ZW. 2008. Basic fibroblast growth factor-induced neuronal differentiation of mouse bone marrow stromal cells requires FGFR-1, MAPK/ERK, and transcription factor AP-1. J Biol Chem. 283(9):5287-5295. doi:10.1074/jbc.M706917200.

Zhang J, Jiao J. 2015. Molecular biomarkers for embryonic and adult neural stem cell and neurogenesis. BioMed Res Int. 2015. doi:10.1155/2015/727542. 